\title{
Research data services in veterinary medicine libraries EC
}

\author{
Erin E. Kerby, MSI \\ See end of article for author's affiliation.
}

DOI: http://dx.doi.org/10.3163/1536-5050.104.4.010

\begin{abstract}
Objective: The study investigated veterinary medicine librarians' experience with and perceptions of research data services. Many academic libraries have begun to offer research data services in response to researchers' increased need for data management support. To date, such services have typically been generic, rather than discipline-specific, to appeal to a wide variety of researchers.
\end{abstract}

Methods: An online survey was deployed to identify trends regarding research data services in veterinary medicine libraries. Participants were identified from a list of contacts from the MLA Veterinary Medical Libraries Section.

Results: Although many respondents indicated that they have a professional interest in research data services, the majority of veterinary medicine librarians only rarely or occasionally provide data management support as part of their regular job responsibilities. There was little consensus as to whether research data services should be core to a library's mission despite their perceived importance to the advancement of veterinary research. Furthermore, most respondents stated that research data services are just as or somewhat less important than the other services that they provide and feel only slightly or somewhat prepared to offer such services.

Conclusions: Lacking a standard definition of "research data" and a common understanding of precisely what research data services encompass, it is difficult for veterinary medicine librarians and libraries to define and understand their roles in research data services. Nonetheless, they appear to have an interest in learning more about and providing research data services.

Keywords: Library Science, Librarians, Library Services, Data Collection, Data Curation, Veterinary Medicine

The library literature has documented how the roles of libraries and librarians have changed over the past several decades as a direct result of advances in technology. Research data management (RDM), which broadly refers to the management of data throughout its life cycle [1], is one area that academic libraries in particular are exploring. Many federal funding agencies are beginning to require a data management plan be included in grant applications, but these funders do not provide much guidance on how this should be done. In response, many academic libraries have taken on a leadership role by spearheading a research data service, often coordinating with other stakeholders at their respective institutions [2-5].

A supplemental appendix is available with the online version of this journal.
To date, the services offered have been primarily educational, rather than technical, but this is changing as librarians gain knowledge and skill in data management. Health sciences libraries have been following a similar path as academic libraries into RDM by offering services such as consulting on data management plans, assisting with finding and citing data, educating researchers and students on best practices in data management, and annotating and describing data [6-8]. Some libraries have hired staff specifically to provide and manage such services, but many librarians have simply incorporated one or more of these services into their regular job responsibilities. A recent systematic review identified a number of new roles for health sciences librarians, including the emerging role of "data management librarian" [9]. 
While many librarians have begun developing knowledge and skills in data management, it remains a challenge for them to do so for one reason in particular. Although certain commonalities exist on a broad scale, data management practices and standards vary considerably across disciplines and even within them. Several studies have explored the differences amongst disciplines [10-12]; for example, the propensity of researchers in certain disciplines to store and/or backup data on college or departmental servers. Adding even more complexity to the picture, Weller and Monroe-Gulick found that research methodology has just as much bearing as discipline on data management practices [13]. For subjectspecialist librarians who are interested in providing research data services, it is critical to understand how the culture of a particular discipline affects data management practices.

Similar to health sciences librarians, veterinary medicine librarians often straddle the line between clinical and basic science when working with faculty, students, and researchers. While the distinction between these two areas may seem arbitrary, there is evidence that the differences have a significant impact on library resources and services [14]. Similarly, data management practices are likely to be different for clinical and basic science researchers, and potentially data service needs as well. For example, basic sciences researchers in medicine typically produce larger quantities of data and are more likely to share these data than clinical and applied science researchers [11].

\section{METHODS}

An online survey consisting of eighteen questions was created with the objective of capturing veterinary medicine librarians' experience with and perceptions of research data services (Appendix, online only). Invitations were emailed directly to potential participants, who were identified through an online directory maintained by the Veterinary Medical Libraries Section of the Medical Library Association. Because many of the questions asked about an individual's perceptions, multiple people from each institution were invited to participate. The population was limited to those working at institutions or organizations in North America, as data management policies, practices, and infrastructure vary significantly throughout the world. This survey received exempt status from the University of Illinois Institutional Review Board.

\section{RESULTS}

The population of veterinary medicine librarians and information professionals is relatively small. From a total number of 94 survey invitations sent, 44 usable responses were received, giving a response rate of $47 \%$. The small sample size limits the generalizability of the survey results. Most respondents worked in an academic institution, but a few worked for a nonprofit organization or the federal government.

\section{Current services}

Most respondents (66\%) indicated their institutions or organizations currently offered research data services.

- Most respondents (66\%) said that they rarely or occasionally provided data management support; they were motivated primarily because patrons had requested this support.

\section{Attitudes toward data services}

$36 \%$ said that data services were somewhat less important than their other job activities, while another $29 \%$ said that data services were just as important.

- When asked if data services should be part of their library's core mission, the majority said they felt this was true $(27 \%)$ or very true $(18 \%)$ of what they believed.

- Most respondents (65\%) said that research data services were very important or moderately important to the advancement of veterinary medicine research.

\section{Data service training}

- $34 \%$ said that their library or institution directly provided data service training.

- $73 \%$ said that their institution provided support for them to attend data service training or conferences; however, some commented that this would come out of their general travel budgets.

- $43 \%$ said that they had participated in data service training and would consider doing so again, and $23 \%$ said that although they had not taken any training, they had considered doing so.

\section{Barriers to providing data services}

More than half of respondents (58\%) indicated that they felt only slightly or somewhat prepared to provide data services. 
- When asked if time was a barrier to providing data services, $27 \%$ said it was somewhat of a barrier and $22 \%$ said it was not a barrier.

\section{DISCUSSION}

Federal funding agencies have indicated that more comprehensive and coordinated data management is necessary for the continued advancement of scientific research. Research data services are important because they provide support for researchers to improve their practices and better manage their data. Many academic libraries have recognized this need, and veterinary medicine librarians have as well. Several survey respondents commented that limited access to veterinary research data is a problem when it comes to reproducibility and transparency of the research. Similarly, several other respondents commented that small sample sizes and data sets are a barrier to scientific discovery and advancement in veterinary medicine.

Some survey participants commented that they were not sure what the terms "data management" or "research data services" meant. For example, one respondent said, "It might help to define exactly what is meant by 'research data services," while another said, "Data management can mean a variety of things, depending on the library." This lack of understanding might have made it difficult for participants to answer certain questions. The author purposely did not provide participants with a definition for any of these terms. In fact, no standard definition exists for the term "research data," nor is there a common understanding of what services constitute "research data services."

Results from this survey suggest that this lack of a common definition and understanding is a barrier for veterinary medicine librarians, as well as for their respective libraries, making it difficult to define and understand their roles in the realm of data services. One participant commented that while data services were a high priority, their library was uncertain of how much librarians should be involved. The library literature indicates that this is an issue for academic libraries in general [15], which makes it challenging for librarians to begin and to sustain a dialogue about research data services with each other, with their patrons, and with administrators.

Another barrier to providing data services is a lack of ownership. Veterinary medicine librarians appear to have an interest in research data services, but many do not feel prepared to offer these services. Several factors appear to contribute to their unpreparedness. Data services are not a primary job responsibility for most of the survey participants, which suggests that subject specialist librarians are not expected to be experts in data services. Therefore, there may be little to no incentive for them to pursue a greater role in this area. Additionally, despite their interest in data services, many respondents said they ultimately referred patrons to data management specialists in their libraries.

Even though many participants have attended data service training, are interested in attending more, and have financial support from their institution to do so, it is not clear that they would actually attend more training. It is typically left up to the librarians to decide how to spend their professional development or travel funds, meaning they would have to weigh data services against their official job responsibilities. Furthermore, it would be difficult for them to know which trainings to attend without having a role already defined for them in data services.

Whether libraries in general should pursue a greater role in research data services than they already have is unclear. Some librarians feel that data services are a natural extension of current efforts to support researchers, while others feel that pursuing these services is out of scope. A one-size-fits-all approach to research data management and services may limit libraries' long-term involvement in data services. Studies such as this survey suggest that collaboration within disciplines and across institutions may be a way forward for subjectspecialist librarians who are interested in providing data services. This is particularly true for librarians who are working in nonprofit or federal libraries, where they might not be able to call upon a central research data service at their organizations.

Librarians need to continue to investigate the data practices of the researchers they support to better understand what services are truly needed and how libraries and librarians can act as stewards in the data management life cycle.

\section{ACKNOWLEDGMENTS}

The author thanks Alfred Wallace for his assistance in conducting a statistical analysis and text analysis of the survey data. 


\section{REFERENCES}

1. Heidorn PB. The emerging role of libraries in data curation and e-science. J Libr Administration. 2011;51(78):662-72.

2. Cox A, Verbaan E, Sen B. A new role for academic librarians? Res Data Manag Multimedia Inf Technol. 2012;38(4):29-30.

3. Schlembach MC, Brach CA. Research data management and the role of libraries. In: Xiao N, McEwen LR, eds. Special issues in data management. American Chemical Society (ACS) Symposium Series. 11102012. p. 129-44.

4. Akers KG, Sferdean FC, Nicholls NH, Green JA. Building support for research data management: biographies of eight research universities. Int J Digital Curation. 2014;9(2):171-91.

5. Si L, Xing WM, Zhuang XZ, Hua XQ, Zhou LM. Investigation and analysis of research data services in university libraries. Electronic Libr. 2015;33(3):417-49.

6. Creamer AT, Martin ER, Kafel D, Wood SM. Research data management and the health sciences librarian. Health Sci Libr. 2014:252-74.

7. Reznik-Zellen RC, Adamick J, McGinty S. Tiers of research data support services. J eSci Libr. 2012;1(1):2735.

8. Tenopir C, Sandusky RJ, Allard S, Birch B. Research data management services in academic research libraries and perceptions of librarians. Libr Inf Sci Res. 2014;36(2): 84-90.

9. Cooper ID, Crum JA. New activities and changing roles of health sciences librarians: a systematic review, 19902012. J Med Libr Assoc. 2013 Oct;101(4):268-77. DOI: http://dx.doi.org/10.3163/1536-5050.101.4.008.

10. Tenopir C, Allard S, Douglass K, Aydinoglu AU, Wu L, Read E, Manoff M, Frame M. Data sharing by scientists: practices and perceptions. PLOS One. 2011;6(6): e21101.

11. Akers KG, Doty J. Disciplinary differences in faculty research data management practices and perspectives. Int J Digital Curation. 2013;8(2):5-26.

12. Whitmire AL, Boock M, Sutton SC, Sicilia MA, Cox A. Variability in academic research data management practices: implications for data services development from a faculty survey. Program: Electronic Libr Inf Systems. 2015;49(4).

13. Weller T, Monroe-Gulick A. Understanding methodological and disciplinary differences in the data practices of academic researchers. Libr Hi Tech. 2014; 32(3):467-82.

14. Tennant MR, Cataldo TT. Development and assessment of specialized liaison librarian services: clinical vs. basic science in a veterinary medicine setting. Med Ref Serv Q. 2002 Summer;21(2):21-37.

15. Pinfield S, Cox AM, Smith J. Research data management and libraries: relationships, activities, drivers and influences. PLOS One. 2014;9(12):e114734.

\section{AUTHOR'S AFFILIATION}

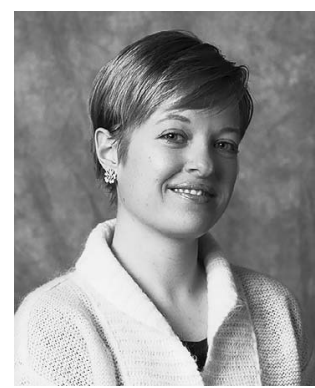

Erin E. Kerby, MSI, ekerb@ illinois.edu, Veterinary Medicine Librarian and Assistant Professor, Veterinary Medicine Library, University of Illinois at Urbana-Champaign, 2001 South Lincoln Avenue, 1257 VMBSB, Urbana, IL 61802

Received March 2016; accepted May 2016 